\title{
Gas Sensing Properties of Nickel Vanadate and Composite of Nickel Vanadate/Polypyrrole
}

\author{
Ai-Lan Yan ${ }^{*}$ \\ Institute of Hydraulic and Environmental Engineering, Zhejiang University of Water Resources and Electric Power, \\ Hangzhou 310018, China
}

(Received January 12, 2018; accepted May 14, 2018)

Keywords: polypyrrole, composite materials, core-shell structure, sensors

In this work, $\mathrm{Ni}_{3} \mathrm{~V}_{2} \mathrm{O}_{8}$ particles were synthesized by a chemical method and sintered, and then, polypyrrole (PPy) films were deposited onto the surface of the $\mathrm{Ni}_{3} \mathrm{~V}_{2} \mathrm{O}_{8}$ particles by in situ chemical polymerization. The morphology and structure of these materials were characterized. Morphological observation proved that the PPy film was well dispersed and completely coated onto the surface of the $\mathrm{Ni}_{3} \mathrm{~V}_{2} \mathrm{O}_{8}$ particles. The $\mathrm{Ni}_{3} \mathrm{~V}_{2} \mathrm{O}_{8}$ particles showed high response to volatile organic gases at $300{ }^{\circ} \mathrm{C}$. The composite of $\mathrm{Ni}_{3} \mathrm{~V}_{2} \mathrm{O}_{8} / \mathrm{PPy}$ exhibited high response to $\mathrm{NH}_{3}$ and $\mathrm{NO}$ at $150{ }^{\circ} \mathrm{C}$, showing great potential for detecting these gases.

\section{Introduction}

Gas sensors with high performance have attracted extensive attention nowadays for ensuring the safety of working and living environments. Great emphasis is being given to nanostructured metal oxides as a sensor material because of their high response and low working temperature. Thus, various n-type and p-type metal oxide nanomaterials, such as $\mathrm{SnO}_{2}, \mathrm{Co}_{3} \mathrm{O}_{4}$, and $\mathrm{WO}_{3}$, as well as their composites have been intensively explored for use in gas sensors. ${ }^{(1-4)}$ Among them, bimetallic oxide systems are of great interest in the fields of catalysis, electrochemistry, and microelectronics. As a bimetallic oxide, nickel vanadate $\left(\mathrm{Ni}_{3} \mathrm{~V}_{2} \mathrm{O}_{8}\right)$ is composed of magnetic $\mathrm{Ni}^{2+}$ and nonmagnetic $\mathrm{V}^{5+} \cdot{ }^{(5)}$ It has attracted much attention in condensed matter physics owing to its unique magnetic and dielectric behavior. ${ }^{(6)}$ Meanwhile, it has been used as an anode material for Li-ion batteries, ${ }^{(7-9)}$ an electrode material for supercapacitors, ${ }^{(10,11)}$ and a photocatalyst, ${ }^{(12)}$ amongst other uses. However, there have been very few reports on the gas sensing properties of $\mathrm{Ni}_{3} \mathrm{~V}_{2} \mathrm{O}_{8}$ until recently. Liu et al. ${ }^{(13)}$ prepared $\mathrm{Ni}_{3} \mathrm{~V}_{2} \mathrm{O}_{8}$ by the sol-gel method with sintering at $1000{ }^{\circ} \mathrm{C}$. The response of nickel vanadate to $100 \mathrm{ppm} \mathrm{NH}_{3}$ was about $-62 \mathrm{mV}$ at $650{ }^{\circ} \mathrm{C}$. It was reported that $\mathrm{Ni}_{3} \mathrm{~V}_{2} \mathrm{O}_{8}$ showed a lower response to $200 \mathrm{ppm}$ acetone at $600{ }^{\circ} \mathrm{C}$ than $\mathrm{Zn}_{3} \mathrm{~V}_{2} \mathrm{O}_{8} .{ }^{(14)}$ The above sensors using $\mathrm{Ni}_{3} \mathrm{~V}_{2} \mathrm{O}_{8}$ showed a rather high operating temperature of at least $600{ }^{\circ} \mathrm{C}$, requiring high energy consumption. A way of reducing its working temperature is thus an urgent topic.

Metal oxide films prepared with small particles for gas sensors are usually 1 to $10 \mu \mathrm{m}$ thick,

*Corresponding author: e-mail: yal200@126.com

http://dx.doi.org/10.18494/SAM.2018.1907 
and the speed of electron diffusion to the external surface of the film inside the particles will be limited. Then, coating a conductive polymer on the surface of the metal oxide can yield a sandwich-like film with electrically conductive layers on both sides of the particles, which will then improve the electrical performance and stability of the sensors. ${ }^{(15,16)}$ To obtain an enhanced gas sensing material, we fabricated $\mathrm{Ni}_{3} \mathrm{~V}_{2} \mathrm{O}_{8}$ and its composite by coating its surface with conductive polypyrrole (PPy) film. Then, their gas sensing performances were briefly compared and investigated.

Volatile organic gases (VOGs) are emitted in many industrial activities and are toxic or carcinogenic in nature to human health. Meanwhile, gases containing nitrogen, such as ammonia and NO, are also toxic and their concentrations in air should be stictly controlled. Effective methods to monitor VOGs and nitrogen containing gases have been in demand for atmospheric environmental measurement and human health monitoring. Thus, the gas sensing performance of $\mathrm{Ni}_{3} \mathrm{~V}_{2} \mathrm{O}_{8}$ and $\mathrm{Ni}_{3} \mathrm{~V}_{2} \mathrm{O}_{8} / \mathrm{PPy}$ to the above gases is studied and reported in this work. To the best of our knowledge, there has been little related research in this field until now.

\section{Experimental Procedure}

\subsection{Preparation of metal oxides and composite}

$\mathrm{Ni}_{3} \mathrm{~V}_{2} \mathrm{O}_{8}$ was prepared by coprecipitation followed by calcination. In a typical procedure, $\mathrm{NH}_{4} \mathrm{VO}_{3}(2 \mathrm{mmol})$ and $\mathrm{NiCl}_{2}(0.4 \mathrm{mmol})$ were dissolved in $40 \mathrm{~mL}$ deionzed water at $80{ }^{\circ} \mathrm{C}$ to form a homogeneous solution under stirring. Then $5 \mathrm{mmol}$ hexamethylenetetramine was added into the above solution to gradually form a yellow suspension. After $4 \mathrm{~h}$ of reaction at $80^{\circ} \mathrm{C}$, the resulting precipitate was filtered off, washed with water, and then dried at $90{ }^{\circ} \mathrm{C}$ to obtain a precursor. The precursor was calcined at $800^{\circ} \mathrm{C}$ in air for $1 \mathrm{~h}$ to obtain the final oxides.

The process for coating PPy on the surface of nickel vanadate particles was conventional in situ chemical polymerization. In a typical process, $20 \mathrm{mg}$ sodium dodecyl sulfate and $50 \mathrm{mg}$ $\mathrm{Ni}_{3} \mathrm{~V}_{2} \mathrm{O}_{8}$ particles were dispersed into $50 \mathrm{~mL}$ water and stirred for $3 \mathrm{~h}$. Then, $2.585 \mu \mathrm{L}$ pyrrole was added into the above aqueous mixture and stirred for $1 \mathrm{~h}$. $1.1 \mathrm{~mL}$ aqueous solution of $\mathrm{FeCl}_{3}$ with a concentration of $0.1 \mathrm{~mol} / \mathrm{L}$ was transferred into the reaction system and stirred for $4 \mathrm{~h}$. $\mathrm{Ni}_{3} \mathrm{~V}_{2} \mathrm{O}_{8} / \mathrm{PPy}$ was then obtained after filtration and washing with water.

\subsection{Material characterization and gas sensing measurements}

The phase of the product was characterized by X-ray diffraction (XRD) using $\mathrm{Cu} \mathrm{K}_{\alpha}$ irradiation at $40 \mathrm{kV}$. SEM images were obtained using a scanning electron microscope (Hitachi S-4800). TEM was used to study the morphology and microstructure of the samples.

For gas sensing measurements, $\mathrm{Ni}_{3} \mathrm{~V}_{2} \mathrm{O}_{8}$ and $\mathrm{Ni}_{3} \mathrm{~V}_{2} \mathrm{O}_{8} / \mathrm{PPy}$ were mixed with a suitable amount of distilled water to form a homogeneous paste. It was then painted onto ceramic substrates with $\mathrm{Ag}-\mathrm{Pd}$ interdigital electrodes and dried at $120^{\circ} \mathrm{C}$. The gas-sensing properties were measured in an intelligent gas sensing analysis system (CGS-1TP, Beijing Elite Tech Co. Ltd., China). This system offers external temperature control from room temperature to 
$500{ }^{\circ} \mathrm{C}$ with a precision of $1{ }^{\circ} \mathrm{C}$. The target gas was injected into the test chamber $(18 \mathrm{~L}$ in volume) and it was mixed with air by two interior fans. When the resistance of the electrode researched a new constant value, the test chamber was opened to recover the sensor by exposure to air. A specific amount of VOGs in the liquid state was injected onto a flat heater inside the chamber of the gas sensing system and then immediately evaporated into gas so as to fill the chamber uniformly. ${ }^{(17)}$ The gas response was defined as $S=[(R a-R g) / R g] \times 100$, where $\mathrm{Ra}$ and $\mathrm{Rg}$ denote the resistances of the sample in air and in the target gas, respectively. ${ }^{(18)}$

\section{Results and Discussion}

We adopted two low calcination temperatures of 300 and $500{ }^{\circ} \mathrm{C}$ for $1 \mathrm{~h}$. The produced samples all showed poor crystallity with very small particle size, as shown in Fig. S1. In order to obtain highly crystalline product, the calcination temperature should be as high as $800{ }^{\circ} \mathrm{C}$. The XRD patterns of the products are shown in Fig. 1. Most of the reflection peaks can be well assigned to $\mathrm{Ni}_{3} \mathrm{~V}_{2} \mathrm{O}_{8}$ (PDF No. 37-0353), with some weak peaks from the $\mathrm{Ni}_{2} \mathrm{~V}_{2} \mathrm{O}_{7}$ ( $\mathrm{PDF}$ No. 29-0945) phase, as shown in Fig. S2. The quantitative analysis was performed with the HighScorePlus software package (PANlytical, The Netherlands, version 3.0). The mass ratio of $\mathrm{Ni}_{3} \mathrm{~V}_{2} \mathrm{O}_{8}$ to $\mathrm{Ni}_{2} \mathrm{~V}_{2} \mathrm{O}_{7}$ was 89:11, indicating that the main product was crystalline $\mathrm{Ni}_{3} \mathrm{~V}_{2} \mathrm{O}_{8}$. The XRD pattern of $\mathrm{Ni}_{3} \mathrm{~V}_{2} \mathrm{O}_{8} /$ PPy was the same as that of $\mathrm{Ni}_{3} \mathrm{~V}_{2} \mathrm{O}_{8}$, even though it was coated with PPy, implying that PPy films were amorphous and had little effect on the structure of metal oxide.

The morphologies of $\mathrm{Ni}_{3} \mathrm{~V}_{2} \mathrm{O}_{8}$ and its composite were characterized by SEM and TEM. Figure 2(a) shows a typical SEM image of $\mathrm{Ni}_{3} \mathrm{~V}_{2} \mathrm{O}_{8}$ particles. The size of grains is mainly from 0.5 to $1.0 \mu \mathrm{m}$. The TEM image in Fig. 2(b) proves that they are solid with a smooth surface and the electrode diffraction pattern in the inset confirms the single-crystalline nature. The SEM image in Fig. 2(c) shows the rough surface of $\mathrm{Ni}_{3} \mathrm{~V}_{2} \mathrm{O}_{8} / \mathrm{PPy}$ caused by the presence of PPy films on the surface of $\mathrm{Ni}_{3} \mathrm{~V}_{2} \mathrm{O}_{8}$. Figure 2(d) shows a typical TEM image, where the PPy film is

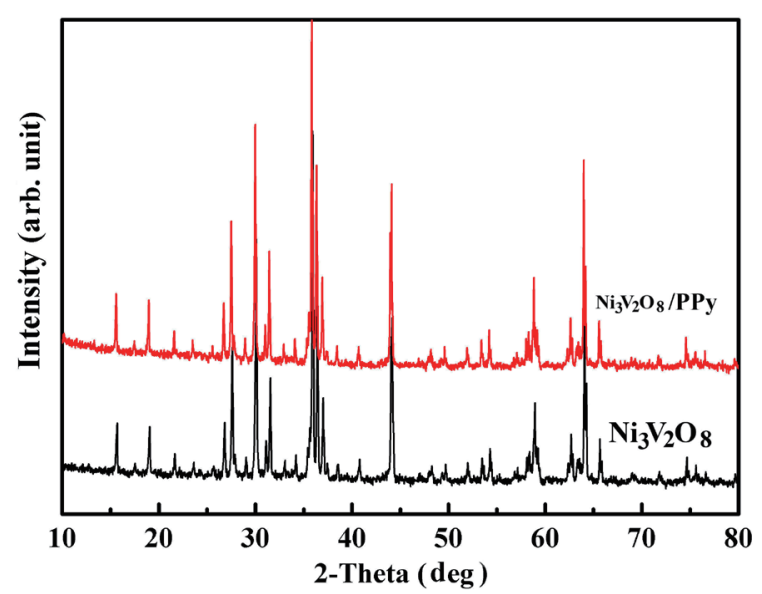

Fig. 1. (Color online) XRD patterns of $\mathrm{Ni}_{3} \mathrm{~V}_{2} \mathrm{O}_{8}$ and $\mathrm{Ni}_{3} \mathrm{~V}_{2} \mathrm{O}_{8} / \mathrm{PPy}$.

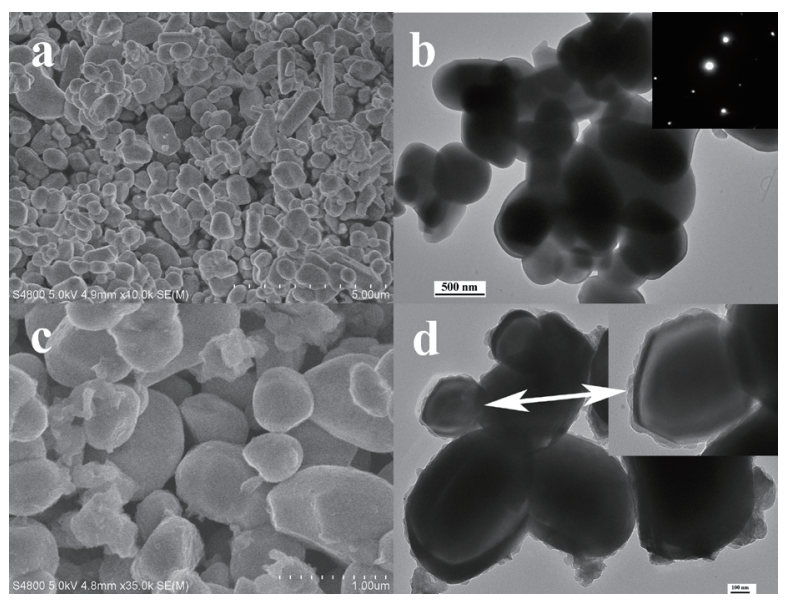

Fig. 2. SEM and TEM images of (a), (b) $\mathrm{Ni}_{3} \mathrm{~V}_{2} \mathrm{O}_{8}$ and (c), (d) $\mathrm{Ni}_{3} \mathrm{~V}_{2} \mathrm{O}_{8} / \mathrm{PPy}$. 
coated on the oxide particles. The inset is an enlarged view of a $\mathrm{Ni}_{3} \mathrm{~V}_{2} \mathrm{O}_{8}$ particle. Its surface is completely coated by PPy film with a thickness of about $10 \mathrm{~nm}$. The core-shell structure could be easily realized by in situ polymerization of pyrrole monomers on the solid particles. ${ }^{(19)}$ Both SEM and TEM observations confirm that PPy films are well coated on the surface of $\mathrm{Ni}_{3} \mathrm{~V}_{2} \mathrm{O}_{8}$ particles after in situ polymerization. The specific surface areas of $\mathrm{Ni}_{3} \mathrm{~V}_{2} \mathrm{O}_{8}$ powder and $\mathrm{Ni}_{3} \mathrm{~V}_{2} \mathrm{O}_{8} / \mathrm{PPy}$ composite were measured to be only 9.25 and $10.56 \mathrm{~m}^{2} / \mathrm{g}$, respectively. Thus, the PPy film has limited effect on improving the specific surface area.

The gas sensing performances of $\mathrm{Ni}_{3} \mathrm{~V}_{2} \mathrm{O}_{8}$ and $\mathrm{Ni}_{3} \mathrm{~V}_{2} \mathrm{O}_{8} / \mathrm{PPy}$ for various gases are shown in Figs. 3(a) and Fig. 3(b), respectively. For $\mathrm{Ni}_{3} \mathrm{~V}_{2} \mathrm{O}_{8}$, the operating temperature was $300{ }^{\circ} \mathrm{C}$, which is much higher than the $150{ }^{\circ} \mathrm{C}$ for $\mathrm{Ni}_{3} \mathrm{~V}_{2} \mathrm{O}_{8} / \mathrm{PPy}$. The resistance of $\mathrm{Ni}_{3} \mathrm{~V}_{2} \mathrm{O}_{8}$ decreased every time in $500 \mathrm{ppm}$ VOGs, which is attributed to the water-forming reaction under high temperature and the addition of electrons to the surface of $\mathrm{Ni}_{3} \mathrm{~V}_{2} \mathrm{O}_{8}$. The $\mathrm{Ni}_{3} \mathrm{~V}_{2} \mathrm{O}_{8}$ sample thus showed n-type material behavior. Its response value to $20 \mathrm{ppm} \mathrm{NO}$ was very low, only about 30.5. However, it showed negligible response to $20 \mathrm{ppm} \mathrm{NH}_{3}$, which may be caused by the reduction reaction between $\mathrm{NH}_{3}$ and $\mathrm{Ni}_{3} \mathrm{~V}_{2} \mathrm{O}_{8}$ at such a high temperature.

$\mathrm{Ni}_{3} \mathrm{~V}_{2} \mathrm{O}_{8} / \mathrm{PPy}$ exhibited a weaker response to $500 \mathrm{ppm}$ VOGs of about $1 / 10$ that of $\mathrm{Ni}_{3} \mathrm{~V}_{2} \mathrm{O}_{8}$, owing to its low operating temperature. However, its responses to $20 \mathrm{ppm} \mathrm{NO}$ and $\mathrm{NH}_{3}$ were very high, about 40.1 and 60.2 , respectively. NO gas caused an increase in resistance, while $\mathrm{NH}_{3}$ led to a decrease. The composite also showed n-type behavior and a strong response to nitrogen-containing gases, though PPy is usually deemed a p-type material. This is considered to be due to the low mass loading of the PPy film.

PPy is a p-type organic conductive polymer created by the oxidation of pyrrole monomer. In this work, pure PPy could be synthesized in the form of nanoparticles by the same process without $\mathrm{Ni}_{3} \mathrm{~V}_{2} \mathrm{O}_{8}$ particles. The gas sensing performances of pure PPy at 300 and $150{ }^{\circ} \mathrm{C}$ were also measured. Pure PPy showed negligible response to VOGs and $\mathrm{NH}_{3} / \mathrm{NO}$ at $300{ }^{\circ} \mathrm{C}$

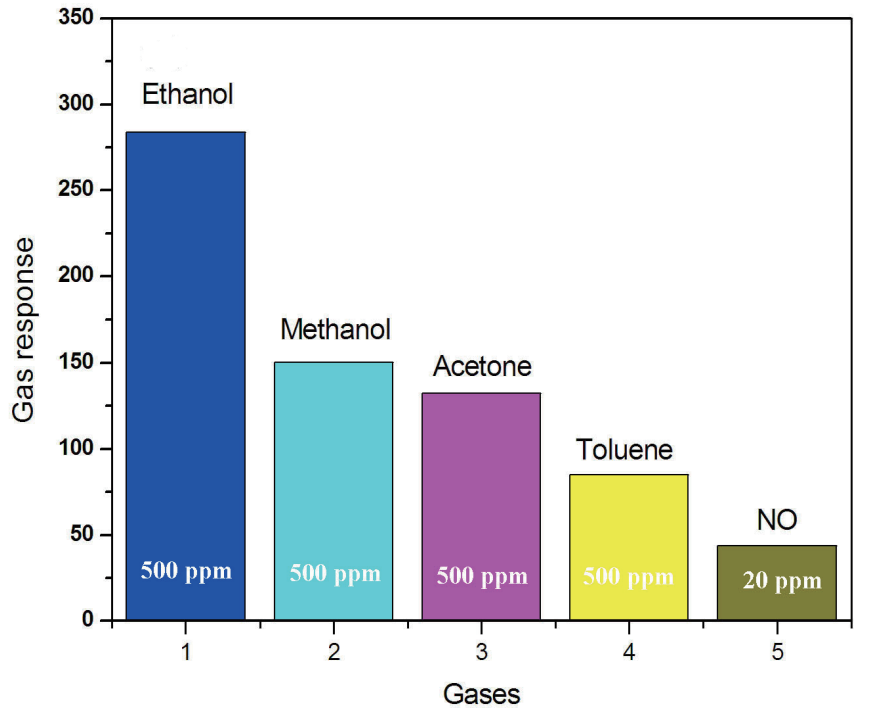

(a)

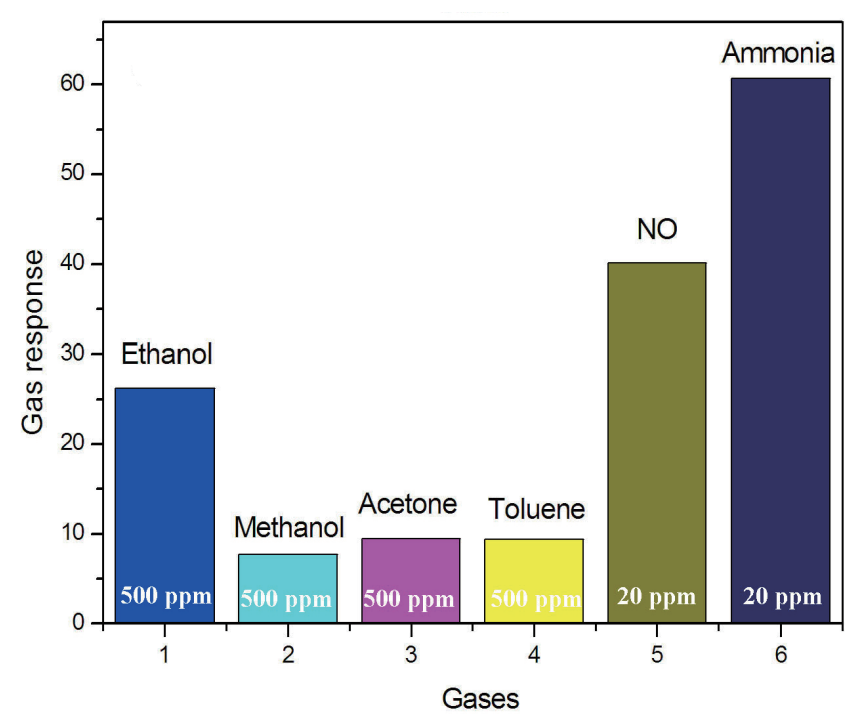

(b)

Fig. 3. (Color online) Responses of (a) $\mathrm{Ni}_{3} \mathrm{~V}_{2} \mathrm{O}_{8}$ at $300{ }^{\circ} \mathrm{C}$ and (b) $\mathrm{Ni}_{3} \mathrm{~V}_{2} \mathrm{O}_{8} / \mathrm{PPy}$ at $150{ }^{\circ} \mathrm{C}$ to various gases of different concentrations. 
owing to its severe degradation at such a high temperature. Although it exhibited very limited degradation at $150{ }^{\circ} \mathrm{C}$, pure PPy film showed a relatively low response of about 18 to $20 \mathrm{ppm}$ $\mathrm{NH}_{3}$. However, the composite of $\mathrm{Ni}_{3} \mathrm{~V}_{2} \mathrm{O}_{8} / \mathrm{PPy}$ exhibited a much higher response (ca. 3.4 times) than that of pure PPy. The mechanism of PPy to $\mathrm{NH}_{3}$ is proposed to be deprotonation/ protonation through adsorption/desorption of $\mathrm{NH}_{3}$ on the PPy surface. ${ }^{(20)}$ Its response to 500 ppm VOGs was rather low, less than 2, because of the hydrogen bonding between the vapor molecules and the PPy polymer chains. Meanwhile, its response to $20 \mathrm{ppm}$ NO was also not high, only about 8 in value.

The synergistic interaction between PPy and $\mathrm{Ni}_{3} \mathrm{~V}_{2} \mathrm{O}_{8}$ particles leads to the formation of $\mathrm{p}-$ $\mathrm{n}$ junctions, electrons diffusion into p-type PPy from $\mathrm{Ni}_{3} \mathrm{~V}_{2} \mathrm{O}_{8}$, and an increase in depletion barrier height, resulting in an improved response of the material. ${ }^{(19)}$ For p-type PPy, when it interacts with $\mathrm{NH}_{3}$, the electron transfer from $\mathrm{NH}_{3}$ to PPy holes induces a decrease in conductivity. ${ }^{(20,21)}$ When interacting with NO, the diffusion of electrons from PPy to NO will lead to the reverse process. The dedoping/doping processes can easily occur in the presence of $\mathrm{NH}_{3}{ }^{(22,23)}$ and $\mathrm{NO}$ gases. However, the $\mathrm{Ni}_{3} \mathrm{~V}_{2} \mathrm{O}_{8} / \mathrm{PPy}$ composite in this work behaved as an n-type material. It operated at a low temperature and showed a strong response to low concentrations of $\mathrm{NH}_{3}$ and $\mathrm{NO}$, suggesting its potential for application in detecting these gases. Further work on the high loading PPy is being undertaken.

\section{Conclusions}

A high calcination temperature caused a high crystallinity and large grain size of $\mathrm{Ni}_{3} \mathrm{~V}_{2} \mathrm{O}_{8}$. The deposition of PPy to construct a core-shell structure was easily carried out by in situ chemical polymerization. $\mathrm{Ni}_{3} \mathrm{~V}_{2} \mathrm{O}_{8}$ showed a strong response to VOGs at $300{ }^{\circ} \mathrm{C} . \mathrm{Ni}_{3} \mathrm{~V}_{2} \mathrm{O}_{8} / \mathrm{PPy}$ exhibited a marked response to $\mathrm{NH}_{3}$ and $\mathrm{NO}$ at $150^{\circ} \mathrm{C}$.

\section{Acknowledgments}

This work was supported by Zhejiang Provincial Natural Science Foundation of China (Nos. LY17D030001 and LY15E090005), Zhejiang Basic public welfare research pro (LGN18E090002).

\section{References}

1 J. P. Cheng, J. Wang, Q. Q. Li, H. G. Liu, and Y. Li: J. Ind. Eng. Chem. 44 (2016) 1.

2 T. Akamatsu, T. Itoh, N. Izu, and W. Shin: Sens. Mater. 28 (2016) 1191.

3 J. M. Xu and J.P. Cheng: J. Alloys Compd. 686 (2016) 753.

4 T. Hyodo, T. Kaino, T. Ueda, K. Izawa, and Y. Shimizu: Sens. Mater. 28 (2016) 1179.

5 Z. Z. He, J. I. Yamaura, and Y. Ueda: Cryst. Growth Des. 8 (2008) 799.

6 I. Cabrera, M. Kenzelmann, G. Lawes, Y. Chen, W. C. Chen, R. Erwin, T. R. Gentile, J. B. Leão, J. W. Lynn, N. Rogado, R. J. Cava, and C. Broholm: Phys. Rev. Lett. 103 (2009) 087201.

7 Y. Li, L. B. Kong, M. C. Liu, W. B. Zhang, and L. Kang: Mater. Lett. 186 (2017) 289.

8 Y. Li, L. B. Kong, M. C. Liu, and L. Kang: RSC Adv. 6 (2016) 90197.

9 C. Wang, D. Fang, H. Wang, Y. Cao, W. Xu, X. Liu, Z. Luo, G. Li, M. Jiang, and C. Xiong: Sci. Rep. 6 (2016) 20826.

10 L. Niu, Y. Wang, F. Ruan, C. Shen, S. Shan, M. Xu, Z. Sun, C. Li, X. Liu, and Y. Gong: J. Mater. Chem. A 4 (2016) 5669.

11 W. B. Zhang, L. B. Kong, X. J. Ma, Y. C. Luo, and L. Kang: RSC Adv. 4 (2014) 41772. 
12 Y. Yan, Y. Yu, D. Wu, Y. Yang, and Y. Cao: Nanoscale 8 (2016) 949.

13 F. Liu, R. Sun, Y. Guan, X. Cheng, H. Zhang, Y. Guan, X. Liang, P. Sun, and G. Lu: Sens. Actuators, B 210 (2015) 795.

14 F. Liu, Y. Guan, R. Sun, X. Liang, P. Sun, F. Liu, and G. Lu: Sens. Actuators, B 221 (2015) 673.

15 W. Ji, J. Ji, X. Cui, J. Chen, D. Liu, H. Deng, and Q. Fu: Chem. Commun. 51 (2015) 7669.

16 A. R. Choudhary and S. A. Waghuley: Mater. Lett. 205 (2017) 36.

17 J. P. Cheng, B. B. Wang, M. G. Zhao, F. Liu, and X. B. Zhang: Sens. Actuators, B 190 (2014) 78.

18 S. F. Ma, J. F. Jia, Y. T. Tian, L. L. Cao, S. L. Shi, X. J. Li, and X. C. Wang: Ceram. Int. 42 (2016) 2041.

19 P. Song, Q. Wang, and Z. X. Yang: Mater. Lett. 65 (2011) 430.

20 J. Sun, X. Shu, Y. Tian, Z. Tong, S. Bai, R. Luo, D. Li, and C. Liu: Sens. Actuators, B 241 (2017) 658.

21 T. Jiang, Z. Wang, Z. Li, W. Wang, X. Xu, X. Liu, J. Wang, and C. Wang: J. Mater. Chem. C 1 (2013) 3017.

22 M. Joulazadeh and A.H. Navarchian: Synthetic Met. 210 (2015) 404.

23 Y. Li, M. F. Jiao, and M. J. Yang: Sens. Actuators, B 238 (2017) 596.

\section{Appendix}

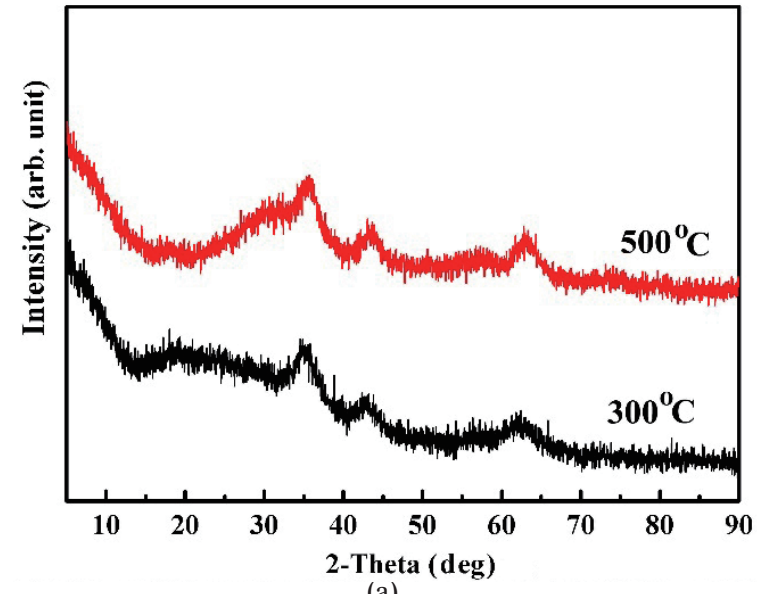

(a)

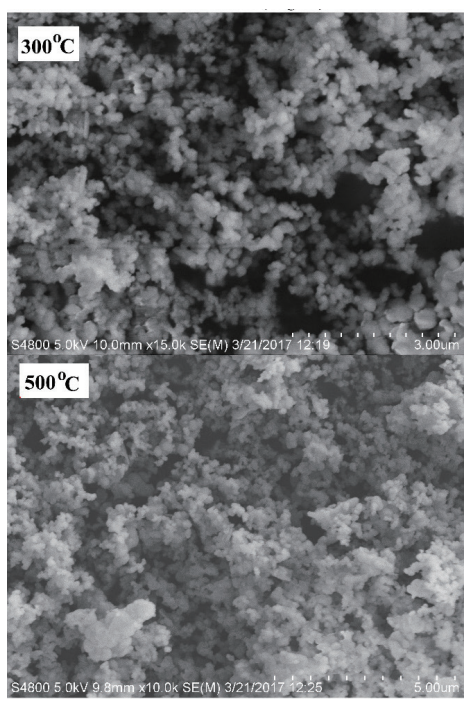

(b)

Fig. S1. (Color online) (a) XRD patterns and (b) SEM images for the $\mathrm{NiVO}_{\mathrm{X}}$ products calcined at 300 and $500^{\circ} \mathrm{C}$.

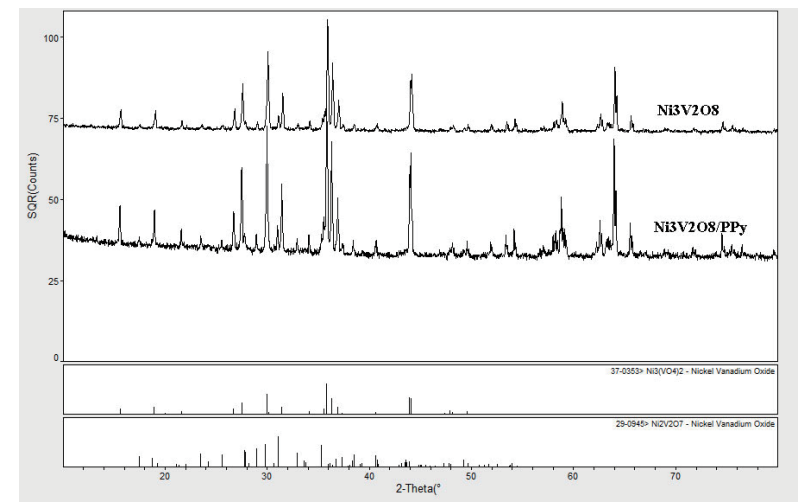

Fig. S2. XRD patterns for two samples after indexing. 